\author{
여성의 안전과 중독 \\ - 음주문제를 중심으로 - \\ 이보혜 ${ }^{1,2} \cdot$ 이수비 $^{2} \cdot$ 이해국 $^{2}$ \\ 고려대학교 대학원 보건과학과 ${ }^{1}$ \\ 가톨릭대학교 의과대학 의정부성모병원 정신과학교실 ${ }^{2}$
}

$=$ Abstract $=$

\title{
Safety and Addiction of Women Focused on the Drinking Problem
}

\author{
Bo Hye Lee ${ }^{1,2} \cdot$ Soo Bi Lee ${ }^{2} \cdot$ Hae Kook Lee ${ }^{2}$ \\ Department of Health Science, Korea University Graduate School ${ }^{1}$ \\ Department of Psychiatry, The Catholic University of Korea, Uijongbu, St. Mary's Hospital ${ }^{2}$
}

\begin{abstract}
There has been a lot of socioeconomic change in Korean society in recent several decades. The increase of the entering the workforce among women and the marketing activity targeting women by alcohol company have made the drinking rate of women increased. These increase of drinking rate among women especially young age group finally result in the increase of the health consequences and the victimization of violence and accidents among women.

Actually, the rate of binge drinking and alcohol use disorders among women has increased from $4.6 \%$ to $6.3 \%$ and from $4.8 \%$ to $5.7 \%$ respectively in recent 5 years, whereas those among men remain stable. These increase of drinking among women has followed by the increase of prevalence of the various health consequences such as the alcoholic liver disease and breast cancers. The one of the most serious case of the health consequences of alcohol is the fetal alcohol syndrome which is developed by maternal drinking. The recent survey conducted in Korea shows the rate of the fetal alcohol syndrome was substantial compared to those of the western countries.

Alcohol causes the problem of safety among women as well as health consequences. The disinhibition effect by alcohol cause the women place the high risk situation. The number of rape victim by the person under the influence of alcohol has increased recently. Further, the recent research showed that drinking women could be more vulnerable to domestic violence.

In conclusion, it is evident that the increase of drinking rate of alcohol among women threaten the health and safety of women herself. To prevent alcohol consequences regarding health and safety among women, we need to develope the evidence based alcohol policy such as public anti advertising activity, screening and brief intervention, specialized treatment facility.
\end{abstract}

Key Words: drinking, women, health, safety

교신저자: 이해국, 경기도 의정부시 금오동 65-1

의정부성모병원 정신과학교실

전화번호: 031-820-3050, 팩스번호: 031-847-3630

E-mail: nplhk@catholic.ac.kr

\section{서 론}

중독은 특정한 물질이나 행위를 과도하게 이용하거 
나 사용해서 스스로 조절하지 못하게 되고, 그로 인해 일상생활 기능과 역할 수행에 문제가 발생하는 것을 말 한다. 중독이라는 용어는 크게 두 가지의 의미가 있으 며, 하나는 ‘독으로 지칭되는 유해 물질에 의한 신체 증 상인 중독(intoxication, 약물 중독)'이라는 의미이고, 또 다른 하나는 '알코올, 마약과 같은 약물 남용에 의한 정신적인 중독이 주로 문제되는 중독(addiction, 의존 증)'을 말한다(Joe 등, 2011). 본고에서 말하고자 하 는 중독은 후자의 경우로 정신적 의존증으로서의 중독 이다.

우리나라의 중독문제는 지속적으로 증가하고 있으 며, 중독으로 인한 문제들은 중독자 개인 뿐 아니라 그 가족 및 사회 전반에까지 심각한 영향을 미치고 있다. 특히 우리나라에서 심각한 사회적 문제로 제기되고 있 는 중독인 알코올, 도박, 인터넷, 마약 중독을 4 대 중독 이라고 분류하였으며, 이러한 4 대 중독 문제에 대한 국 가적 개입의 필요성이 대두되어 최근 관련 법률안이 상 정된 바 있다.

중독은 급성 또는 만성적으로 정신 및 신체기능에 영 향을 주어 건강을 포함한 안전문제에 부정적인 영향을 주며, 이러한 부정적 결과는 여성에서 더 위험성이 증 가할 수 있다. 특히 최근 여성들의 사회적 지위가 향상 되고, 사회진출이 활발해짐에 따라 여성음주가 새로운 사회적 문제로 대두되고 있다. 여성은 남성에 비하여 같은 양의 알코올을 소비했을 때 더욱 강한 신체적 반 응을 일으키며, 알코올 분해효소 $(\mathrm{ADH}$, 알코올 탈수소 효소)의 분해과정에서 여성은 남성의 $50 \%$ 정도만 분해 할 수 있어 같은 양의 술을 마셨더라 하더라고 여성의 경우 상대적으로 더 많은 양의 알코올이 혈중에 남아 있어, 이로 인해 건강에 미치는 영향은 더욱 심각하다 고 할 수 있다(NIAAA, 1990; Kinney, 2000; Jung 2007). 또한 음주의 폐해 역시 여성이 더 큰 것으로 나 타나며, 여성 음주폐해의 대표적인 사례로 유방암의 발 생가능성 증가, 태아알코올증후군(Fetal Alcohol Syndrome) 과 같은 증상을 들 수 있다. 또한 장기간의 음주는 남성의 비해 알코올성 간경화와 간염에 걸릴 확 률이 더욱 높다고 보고된다(Park과 Lee, 2011).
음주문제는 건강상의 폐해 뿐 아니라 사회 안전문제 의 주요인으로도 보고되고 있다. 알코올은 범죄와 관련 하여 병리적인 기능을 가지고 있으며, 폭력범죄의 주된 요인으로 나타난다(Critcholow, 1986). 우리나라 범죄 중 폭행 및 강도, 강간, 살인과 같은 강력범죄의 경우 약 $30 \%$ 이상이 음주상태에서 발생하며(SPO, 2010), 특히 음주로 인한 강간 및 강제추행 등의 성범죄는 매 년 증가하고 있다(KNPA, 2011).

이처럼 우리나라의 중독 문제는 우리사회에 있어 광 범위하게 부정적인 영향을 미치고 있다. 특히 음주문제 는 여성에게 있어서 건강의 문제, 안전의 문제 등 더욱 그 폐해가 크다고 볼 수 있다. 이에 본고에서는 여성 음 주율 및 관련 질환의 변화에 대하여 살펴보고, 이러한 음주문제가 여성의 안전에 어떠한 영향을 미치고 있는 지 그 심각성에 대하여 고찰 할 것이다. 이를 통하여 우 리나라 여성의 음주로 인한 건강 및 안전 문제의 해결 을 위한 대책방향에 대하여 논의하고자 한다.

\section{본 론}

\section{1. 여성음주의 증가}

일반적으로 여성이 남성에 비해 음주의 정도가 낮다 는 것은 국내외를 막론하고 여러 연구를 통하여 잘 알 려져 있으나, 최근 여성들의 사회진출이 활발해짐에 따 라 여성음주가 새로운 사회적 문제로 대두되고 있다.

우리나라 전 국민을 대상으로 국민의 건강 및 영양상 태에 관한 국가 대표통계를 산출하는 국민건강영양조사 (KCDC, 2011)에 따르면, 여성의 월간음주율은 2005 년 32.9\%에서 2011년 44.2\%로 꾸준한 증가추세를 보이고 있다. 음주는 알코올사용장애와 같은 일차적인 정신행동질환을 유발할 뿐만 아니라, 고위험 음주와 같 은 건강위험행동으로도 정의할 수 있는데(Lee와 Lee, 2012), 국민건강영양조사에서는 고위험음주를 주 2회 이상 평균 음주량 7 잔(여자 5잔) 이상 음주로 정의하 고 있다. 고위험음주는 만성적으로 지방간, 간경변을 일 으키며, 각종 암의 발생률을 증가시킬 뿐 아니라 우발 
적 상해나 폭행 등을 발생시킬 수 있어 수많은 건강문 제와 사회문제를 유발한다(Savolainen et al, 1998; Bagnardi et al, 2001). 우리나라 여성의 고위험음주 는 2005년 4.6\%에서 2011년 6.3\%로 증가하는 경향을 보이고 있으며, 특히 20,30대 여성의 고위험 음주가 급격히 증가하였는데, 30 대 여성의 경우 2005년 4.0 $\%$ 에서 2011년 8.8\%로 2배 이상의 증가폭을 보이고 있다(Table 1) (KCDC, 2011).

이와 같은 경향은 정신질환역학실태조사(Seoul $\mathrm{Na}^{-}$ tional University College of Medicine, 2011)에 서도 나타나고 있는데, 알코올사용장애 일년유병률은 2001년에서 2011년 사이 전체적으로 감소하는 추세 이며, 남성의 경우 전 연령대에서 감소한 반면, 여성의 경우 20 대와 30 대에서 유일하게 증가 추세를 보이고 있다. 2001년 20대 여성의 알코올사용장애 일년유병 률은 $4.8 \%$ 에서 2011년 5.7\%로, 30대 여성의 경우 $1.4 \%$ 에서 $2.0 \%$ 로 그 유병율이 증가하였다(Table 2).
이처럼 여성의 문제음주가 증가하는 경향은 여성의 사회진출이 활발해짐에 따른 알코올 노출 증가 뿐 아니 라, 저도주의 소비 증가 현상과 관련이 있음이 시사된 다. 우리나라의 순수알코올소비량은 소폭으로 하락하고 있는데 반하여(OECD, 2012), 전체 주류출고량은 증 가하고 있다는 것은 상대적으로 저도주의 소비가 증가 하고 있다는 것을 대변하며, 2006년 이후 소주의 저도 화 현상이 가속화되는 양상을 보이고 있다. 전체 주류 시장의 20도 미만의 소주비율은 2007년 36.4\%에서 2010년 73.4\%로 급격히 상승하였으며(Table 3) (KARC, 2010), 이러한 경향의 이면에는 젊은 여성층 에서 저도주 소비 증가와 관련이 있음이 시사된다. 주류 업체들이 저도 소주를 출시한 배경이 젊은 층의 고객을 목표로 하며, 여성의 사회진출이 증가됨으로 인해 여성 고객들의 영향력이 커진 것으로 분석하고 있다(KARC, 2010).

Table 1. Prevalence of High-risk Drinking in Female

\begin{tabular}{|c|c|c|c|c|c|c|}
\hline Year & 2005 & 2007 & 2008 & 2009 & 2010 & 2011 \\
\hline $\begin{array}{l}\text { Total } \\
\text { Age (year) }\end{array}$ & 4.6 & 5.0 & 8.4 & 7.3 & 7.4 & 6.3 \\
\hline $19 \sim 29$ & 7.1 & 6.7 & 12.4 & 9.6 & 9.8 & 9.4 \\
\hline 30 39 & 4.0 & 5.5 & 9.5 & 8.3 & 10.5 & 8.8 \\
\hline $40 \sim 49$ & 4.6 & 6.1 & 9.8 & 8.1 & 8.7 & 5.6 \\
\hline 50 59 & 4.1 & 3.5 & 6.2 & 6.5 & 3.9 & 4.3 \\
\hline $60 \sim 69$ & 2.3 & 1.3 & 1.0 & 4.5 & 0.6 & 1.6 \\
\hline $70<$ & 2.5 & 2.2 & 2.8 & 0.8 & 1.5 & 1.8 \\
\hline
\end{tabular}

Table 2. Prevalence of Patients of 12-month Alcohol use Disorders

(Unit: \%)

\begin{tabular}{|c|c|c|c|c|c|c|}
\hline \multirow{2}{*}{ Year } & \multicolumn{3}{|c|}{2001} & \multicolumn{3}{|c|}{2011} \\
\hline & Male & Female & Total & Male & Female & Total \\
\hline Total & 11.0 & 2.6 & 6.8 & 6.6 & 2.1 & 4.3 \\
\hline Age (year) & & & & & & \\
\hline 19 29 & 11.0 & 4.8 & 8.0 & 8.1 & 5.7 & 6.9 \\
\hline 30 39 & 11.6 & 1.4 & 6.7 & 6.9 & 2.0 & 4.5 \\
\hline $40 \sim 49$ & 12.3 & 2.1 & 7.4 & 7.1 & 1.8 & 4.5 \\
\hline $50 \sim 59$ & 8.7 & 1.8 & 5.2 & 6.4 & 0.4 & 3.3 \\
\hline $60 \sim 69$ & 8.0 & - & 3.7 & 3.5 & 0.6 & 1.9 \\
\hline $70 \sim 74$ & - & - & - & 2.7 & 0.0 & 1.1 \\
\hline
\end{tabular}




\section{2. 음주문제로 인한 건강상의 폐해}

적정음주이상의 알코올 섭취는 다양한 질병의 발병 위험을 증가시킨다. 대표적인 질환으로는 알코올성 간 질환과 간경화 등이 있으며, 여성음주가 증가됨에 따라 여성의 음주관련 질환도 증가하는 경향을 보이고 있다.

$\mathrm{WHO}$ 에서 음주와 관련이 있다고 보고된 30개 질환 에 대한 건강보험에서의 총 진료비 및 급여비 지출규모 를 성별에 따라 살펴보면, 남성의 경우 총 진료비 규모 가 2005년 16,327억 원에서 2009년 30,978억 원으 로 1.9 배 증가하였고, 급여비의 경우 1.95 배 $(11,845$ 억 원에서 23,081억 원) 증가하였다. 여성의 경우는 총 진료비 규모는 2005년 15,801억 원에서 2009년 30,248 억 원으로 1.91 배, 급여비는 11,455 억 원에 서 22,527 억 원 1.97 배 증가하여 남성에 비해 증가폭 이 조금 더 컸다(NHIS, 2010). 남성의 음주율이 여성 에 비하여 높으나 관련 질환의 진료비 및 급여비 지출 규모는 비슷하게 나타나며 오히려 여성이 증가폭은 더 컸다. 또한 건강보험심사평가원의 간경화 입원 및 외 래 환자 수를 조사한 결과, 2008년에 비해 2012년 남녀 전체가 증가하는 경향을 보이고 있으며, 특히 남 성에 비해 여성의 경우 그 증가폭이 조금 더 크게 나타 나고 있다(Fig. 1).

여성이 임신 중에 음주를 하게 되면, 이로 인하여 태 아에게는 기형이, 신생아에게는 다양한 문제 행동들이 유발 될 수 있다. 임신 중 음주로 인하여 신생아에게 발 생되는 다양한 문제 행동들을 태아알코올스펙트럼장애 (Fetal Alcohol Spectrum Disorder, FASD)라고 하며(Sokol, 2003), 이러한 태아알코올스펙트럼장애 에는, 중추신경 및 신경발달장애, 특징적 안면기형, 그 리고 발육지체 등의 특징적인 증상을 보이는 태아알코
올증후군(Fetal Alcohol Syndrome, FAS)이 포함 되어 있다(Sokol \& Clarren, 1989).

앞서 살펴본 바와 같이 우리나라 여성의 음주율은 점 차 증가하고 있으며, 특히 가임기 여성인 20, 30대 여 성의 음주율이 최근 급격하게 증가하고 있다. 임산부 를 대상으로 한 연구결과에 의하면 임신 전 음주 경험 이 있는 임산부 가운데 임신 중 금주를 하는 비율이 $54.5 \%$ 로(Min EJ 등, 2012), 외국의 선행연구인 Pirile 등(2000) 연구의 90\%, Patrica \& Abbey (2009) 연구의 $87 \%$ 에 비하면 우리나라의 경우 임산부의 금주 율이 매우 낮은 편임을 알 수 있다.

최근 적극적 사례조사방법을 통한 한국의 태아알코 올증후군의 유병률을 조사한 연구가 진행된 바 있으며, 연구결과 우리나라 태아알코올증후군의 최소 추정 유병 률은 천명 당 5.1명 수준으로(Lee HK, 2012), 이전 외국들의 보고와 비교하여도 결코 낮지 않은 수준이었 다(Fig. 2).

음주는 또한 인두암, 후두암, 간암, 위암, 유방암 등 각종 암과 관련성이 있는 것으로 보고되고 있다(Bagnardi et al, 2001). 최근 음주와 암 사망률과의 연관

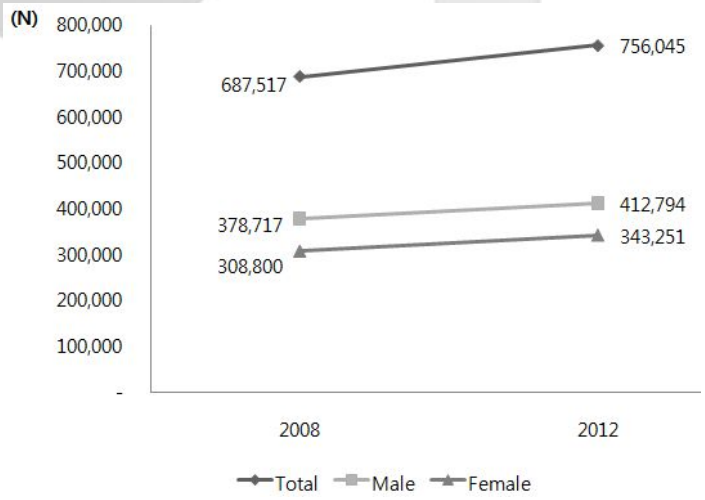

Fig. 1. The number of patients of Liver cirrhosis according to sex (hospitalization+outpatient) (2008, 2012 year)

Table 3. Market Share of Diluted Soju

\begin{tabular}{lrrrrr}
\hline Year & 2005 & 2007 & 2008 & 2009 & 2010.2 \\
\hline$>20 \%$ & $100 \%$ & $63.60 \%$ & $43.10 \%$ & $30.60 \%$ & $26.60 \%$ \\
$18 \sim 20 \%$ & $0 \%$ & $35.90 \%$ & $56.40 \%$ & $67.70 \%$ & $70.20 \%$ \\
$<18 \%$ & $0 \%$ & $0.50 \%$ & $0.50 \%$ & $1.70 \%$ & $3.20 \%$ \\
\hline
\end{tabular}




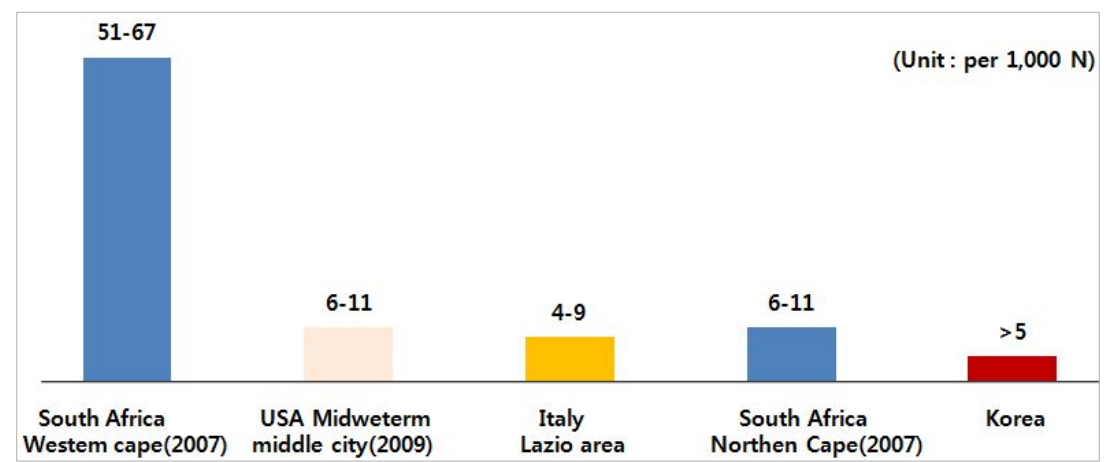

Fig. 2. Comparison of rate of fetal alcohol syndrome

성에 관한 연구에서는 음주량이 1잔에서 3잔으로 증가 함에 따라 모든 암에 의한 사망 위험률이 $22 \%$ 가 증가 하였고, 음주빈도가 주 1 회 미만에서 주3회 이상으로 증가함에 따라 $14 \%$ 위험률이 증가하였다고 보고하였 다. 특히 암에 의한 사망위험률에 있어서 남성은 음주 량이, 여성은 빈도가 많은 영향을 미친다고 밝혔다 (Breslow et al, 2011). 이는 여성은 소량의 음주라도 횟수가 많을수록 암 사망률에 대한 위험이 커진다는 것 을 의미한다.

암 사망률 뿐 아니라 발생률에 있어서도 음주는 그 위험요인으로 작용한다. 음주량이 많을수록 유방암 발 생이 증가하고, 소량에 해당하는 하루에 한잔 정도의 양 에서도 유방암 발생위험도는 증가한다(Lee ES, 2011). 이런 현상은 비교적 많은 양 하루 3 4잔을 마셔야만 그 위험도가 증가하는 다른 암과는 차별화되고 있어, 여성 의 음주에 대한 저항성은 남성보다도 더 약한 상태에 있 다.

2000년도 우리나라 여성의 유방암 사망률은 10 만 명당 4.8명이었는데, 2010년 7.5명으로 10년 사이 1.56배 증가하였으며(Statistics Korea, 2011), 유 방암 발생률 또한 2002년 10만명당 15 34세군 8.6 명, 35 64세군 70.5명에서 2008년에는 9.2명, 98.8 명으로 증가하였다(National Cancer Center, 2012). 이처럼 우리나라 여성의 유방암 사망률 및 발생률 증가 현상은 최근 여성의 사회진출 증가에 따른 음주량 및 고 위험 음주 증가 현상과의 관련성이 시사된다.

\section{3. 음주문제로 인한 안전의 문제}

여성에게 있어 음주는 건강상의 문제 뿐 아니라, 사 회적 안전의 문제 또한 지속적으로 보고되고 있다. $\mathrm{WHO}$ (1990)에서는 음주로 인한 가정내 폭력과 상습적 범죄 의 문제의 심각성을 강조하고 있으며, 음주자에 따라 개 인차는 있으나 일반적으로 음주를 하게 되면 주의가 산 만해지고, 판단력이 흐려지며, 자제력이 감소하는 한편 충동적 - 폭발적으로 행동하거나 망각증상이 발생하는 특징이 있어, 이러한 증상은 음주자 본인뿐만 아니라, 격정범죄, 충동범죄, 과실범죄가 일어나게 되어(Kim, 2012), 가족 및 불측정 다수의 위험을 초래할 수 있다.

Lee 등(2011)의 연구에서, 대검찰청의 범죄분석 (2009) 자료를 분석한 결과 2002년부터 2009년까지 의 전체 범죄 중 평균 $18.0 \%$ 가 음주상태에서 범죄가 발생하였으며, 폭행, 강도, 강간, 살인과 같은 강력범죄 의 경우에는 약 $30 \%$ 이상이 음주상태에서 발생된다고 조사되었다. 특히 여성의 경우 음주로 인한 주취범죄 중에서도 성범죄 피해의 대상이 되고 있으며, 경찰청 범 죄통계(KNPA, 2011)에 따르면 음주관련 강간 및 강 제추행 등 성범죄는 2005년 13,446건에서 2011년 19,498 건으로 매년 증가 경향을 보이고 있다(Fig. 3). 음주는 또한 가정 내 폭력을 초래하는 변인으로서 정 상적인 가정생활을 위협의 대표적 요인으로 지속적으로 보고되고 있다. Roy (1982)의 연구에 의하면 학대받 는 여성의 남편 중 $70 \%$ 가 알코올의존자라고 보고한 바 


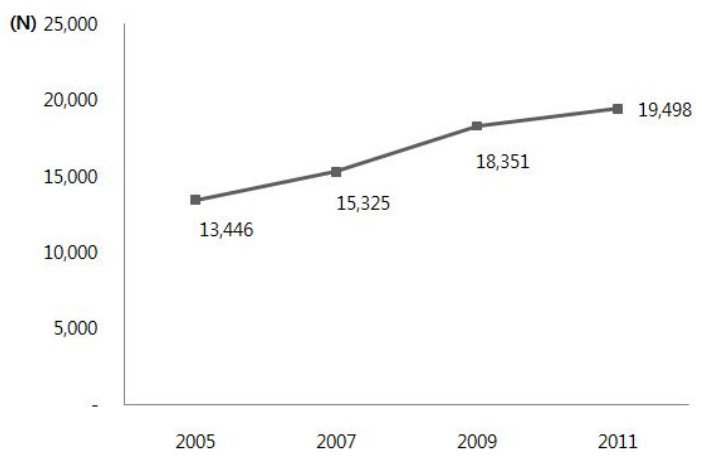

Fig. 3. Alcohol-related sexual crime trend

있으며, Brookoof 등(1997)의 연구에서는 가정폭력 으로 체포된 가해자의 $92 \%$ 가 폭력당시 음주상태로 나 타났다. 음주와 가정폭력에 관한 국내 연구로는 전국 1,000 명을 대상으로 한 한국보건사회연구원의 가정폭 력실태조사에서 가정폭력 원인 중 1 위가 남편의 술버릇 (29.0\%)으로 나타났으며(KIHASA, 1998), 1,205명 의 기혼자를 대상으로 한 $\operatorname{Kim~(1998)ㅇㅢ~ㅇㅕㄴㄱㅜㅇㅔ~ㅇㅢㅎㅏ~}$ 면 남편의 음주정도가 심해질수록 아내 구타율이 유의 하게 증가하였다. 한국복지패널의 2,366 개의 기혼가구 를 대상으로 한 연구에서 또한 문제음주의 수준이 증가 할수록, 음주빈도가 증가할수록, 음주로 인해 일을 하지 못한 경험의 횟수가 증가할수록 배우자에 대한 정신적, 신체적 폭력이 증가하는 것으로 나타났다(Kwon과 Kahang, 2007).

\section{결 론}

여성의 사회적 진출 및 지위가 향상됨에 따라, 주류 사회의 문화인 음주에 대한 취약성도 증가하게 되었다. 또한 주류회사의 마케팅 또한 젊은 여성을 주 대상으로 한 전략이 적용되고 있다. 이러한 사회·문화경제적 환 경의 변화는 여성의 음주를 증가시키는 방향으로 작용 하게 된다. 실제 가임기 젊은 여성을 중심으로 음주율 상승이 나타나고, 이는 결국 음주로 인한 다양한 질환, 즉, 정신장애로서 알코올사용장애와 신체질환으로서 간 질환, 암 등 다양한 알코올기인 신체질환의 발병률이 상승하는 것으로 귀결되고 있다. 뿐만 아니라, 여성에서
음주관련질환 치료율과 치료비용이 상승폭도 남성보다 크게 증가하고 있다. 가임기 여성의 음주는 임산부 음 주로 인한 태아알코올증후군과 같은 치명적 문제도 유 발하는데, 국내 조사결과도 우리나라의 상황이 이미 안 전한 상황이 아님을 말해주고 있다.

음주는 탈억제 작용으로 인해 다양한 급성 행동문제 와 이로 인한 범죄, 사고 등을 유발할 수 있는데, 사회 적 약자인 여성이 특히 이러한 위험에 취약하다. 실제, 주취상태에서의 성폭력이 증가하고 있으며, 가정폭력에 있어 가해자, 피해자 모두에 있어 음주가 위험요인으로 작용하고 있음이 보고되고 있다.

이렇듯 음주가 젊은 여성에서 증가하고 있으며, 이로 인한 건강과 안전의 폐해가 여성 자신에서 증가하고 있 는 경향을 나타내고 있다. 따라서, 여성안전의 측면에서 여성에서의 음주와 음주로 인한 폐해를 예방하고 완화 할 수 있는 정책을 시급히 도입할 필요가 있다. 여성음 주의 폐해에 대한 인식향상을 위한 공익미디어 홍보의 강화, 접근성이 높은 예방교육, 조기개입 서비스의 시 행, 여성의 상황을 고려한 전용 치료서비스 제공 시설 등이 도입가능한 정책의 예가 될 수 있다. 이러한 정책 의 시행을 통해 여성의 안전과 건강 향상에 큰 도움이 될 수 있을 것으로 판단된다.

\section{참고문헌}

Bagnardi V, Blangiardo M, La Vecchia C, Corrao G. A meta-analysis of alcohol drinking and cancer risk, British Journal of Cancer 2001;85:1700-1705 Breslow RA, Che nCM, Graubard BI, Mukamal KJ. Prospective Study of Alcohol Consumption Quantity and Frequency and Cancer-Specific Mortality in the US Population. American Journal of Epidemiology 2011;174:1044-1053

Brookoff D, O Breidn K, Cook C, Thompson T, Williams C. Characteristics of Participants in Domestic violence: Assessment at the scene of domestic assault. Journal of the American Medical Association 1997;227:1369-1373

Critchlow B. The Powers of John Barleycorn; Beliefs about the Effects of Alcohol on Social behavior. 
American Psychologist. 1986

KCDC Korea Centers for Disease Control and Prevention. The Fifth Korea National Health and $\mathrm{Nu}^{-}$ trition Examination Survey (KNHANES V-2). 2011

Kinney J. Loosening the Grip: A Handbook of Alcohol Information, Boston. MA: McGraw Hill. 2000

Kim HJ. Study on The Interrelationship Between Alcohol and Crimes: Focused on the Admissibility and Tolerant Recognition on the Alcohol-Related Crimes. The Korean Civic Ethics Society 2012; 25:1-30

Kim JY. Alcohol Consumption and Family Violence: Data from Korea National Family Violence Survey. Korean Journal of Family Therapy 1998;4:177198

KIHASA The Korea Institute for Health and Social Affairs. A Study on Conceptualization and Current Situation of Domestic Violance. KIHASA. 1998

Kwon TY, Kahng SK. Influence of alcohol related factors in husband on the wife . Korea Academy of Mental Health Social Work 2007:283-300

Lee ES. Alcohol and Breast Cancer, Health Life Symposium 2011:74:3

Lee HK. Epidemiology of Fetal Alcohol Syndrome in Korea, KCDC. 2012

Lee HK, Lee BH. The Epidemiology of Alcohol Use Disorder. The Journal of Diabetes 2012;13:69-75

Lee HK, Lee KS, Kim HS, Jung S, Seo JS et al. Treatment Activation Plans to Reduce and Prevent Alcohol-Related Harms, Ministry of Health and Welfare. 2011

Min EJ, Kim SG, Lee JS, Jung WY, Lee DH et al. Changes in the Drinking Behavior of Korean Women During Pregnancy between 1997 and 2008. J Korean Academy of Addiction Psychiatry 2012; 16:91-94

National Cancer Center, Annual report of cancer statistics in Korea in 2010, KNCC, 2012.

NHIS National Health Insurance Service. Alcohol on Public Health Spending in Korea, Health Insurance Policy Research Institute. 2010.

NIAAA National Institute of Alcohol Abuse and Alcoholism, Alcohol and Women, Alcohol Alert No. $10 \mathrm{Ph} 290$. Abailable at http://www.niaaa.nih.gov, 2000

OECD. Health Data 2012. June 2012. http://www. oecd.org/health/healthdata. 2012
Joe KH, Kwon DH, Kim DJ, Kim SM, Kim HO et al., The Study of Addiction and Rehabilitation. Hakjisa, 2011.

Jung S. Factors Influencing Problem Drinking among Female College Students in Korea. Mental Health \& Social Work 2007;27:176-198

Park HR, Lee J. When Women Drink: What to Drink in What Context is? The Korean Journal of Woman Psychology 2011;16:243-263

Patrica AH, Abbey CS. Alcohol and drug use before and during pregnancy.: An examination of use patterns and predictors of cessation. Maternal Child Health J 2009;13:386-394

Pirie PL, Lando H, Curry SJ, McBride CM, Grothaus LC. Tobacco, alcohol, and caffeine use and cessation in early pregnancy. Am J Prev Med 2000;18: $54-61$

Roy M. The abusive partner: An analysis of domestic battering. in Alcohol, drug, and partner abuse, edited by M. Roy. NY: Van Nostrand and Reinhold. 1982

Savolainen VT, Liesto K, Mannikko A, Pentilla A, Karhunen PJ. Alcohol consumption and alcoholic liver disease: evidence of a threshold level of effects of ethanol. Alcohol Clin Exp Res 1993;17: $1112-1117$

Seoul National University College of Medicine. Korean Epidemiologic Catchment Area (KEKA) survey. 2011

Sokol RJ, Delaney-Black V, Nordstrom B. Fetal alcohol spectrum disorder. JAMA 290:2996-2999: 2003

Sokol RJ, Clarren SK. Guidelines for use of terminology describing the impact of prenatal alcohol on the offspring. Alcohol Clin Exp Res 13;597-598: 1989

SPO The Supreme Public Prosecutors Office Republic of Korea. Crime Analysis. 2010.

Statistics Korea, Causes of Death Statistics in 2010, Statistics Korea, 2011.

KARC Korea Alcohol Research Center. A Study on Establishing Identity for Soju degree. 2010

KNPA Korean National Policy Agency. Crime Statistics. 2011

WHO World Health Organization. Management of Drinking Problems, WHO Regional Publications European Series, No 32. 1990 